\title{
Education and Training of Modern Designers under the Background of Transformation and Upgrading of Creative Industries in Suzhou
}

\author{
Yan Su \\ Media and College of Visual Arts, Suzhou University of Science and Technology, Jiangsu Suzhou \\ 215009, Jiangsu, China \\ *goldbook@163.com
}

Keywords: Creative industries; Vulgarization; Ecological crisis

\begin{abstract}
Creative industry has become an important industrial model by leaps and bounds with the arrival of the age of the knowledge economy. Chinese creative industry has entered a hitherto unknown period of strategic opportunities in the influence of global creative economy and development. However, we encounter some problems including the shortage of creative talents, lagging of the creative design education and other issues. It needs to think about and discuss the education and training of the modern design talents under the background of transformation and upgrading of domestic industrial clusters.
\end{abstract}

\section{Introduction}

The definition of the term "creative industries" can be referenced in the report of Shanghai statistics Bureau in which it was called a new hot spot of international industry development. In the statistical category creative industries are of a collection of industries that engage in the manufacture, circulation, and provision of services of cultural connotations. The creative industry itself contains three contents: culture, creativity and industry[1]. They represent the cultural and creative industries to being a whole that is distinct and interrelated, which constitute the cultural connotation of creative industries. For the art design subjects, the education and training of creative talents not only have good imagination and creativity, deep thought, good at innovation and change, full of personality, but also are good at dealing with people, have strong sense of responsibility and team spirit. Moreover, it needs to construct a new teaching pattern: the practical teaching of art design subject[2].

Creative industries as a product of culture of science, technology and economic integration. Now it has been regarded as one of the world's most promising industry in the 21 century and has attached a great importance to the developed countries because of the unique value orientation, wide industry field and rapid growth. The scale and maturity of creative industries have become an important index to measure the comprehensive competitiveness of a country or a city. Recent years, the huge industrial and enormous economic benefits of the creative industry have been recognized all over the world[3]. The creative economy in the world grows very fast, which creats $22 \$$ billion a day, increasing with a rate of 5\%. Last year, the creative industries accounted for $25 \%, 17 \%$, and $16 \%$ in GDP of the United States, Britain and Japan[4].

At present, the creative industries of China are facing the surging wave of creative industries and trends. The creative industry got a profits of $10^{7} ¥$, accounting for $10.85 \%$ of the total assets of all enterprises, and with a average assets up to $27190 ¥$ [5]. The annual business income of the creative enterprises is $2.3 \times 10^{6} ¥$, accounting for $5.22 \%$ of the all enterprises operating income. Compared with 2007, the proportion of creative industries in GDP in 2008 increased from $2.49 \%$ to $2.52 \%$, showing that creative industries in China have a good tendency of development[5]. However, the creative industries of China in the scale, output value, the proportion of GDP and the sense of innovation have a large gap with the developed countries. The cultural industry of China is required to enhance continully and largely, said by Liu Changle of the chairman of the board of directors in Phoenix TV. For a along time, we just fabricate products of other countries, lack of creating the original products. For example, Bobbi dolls, the processing profit in China get only $2 \%$ of the total 
value. "Kung Fu Panda" and "Taishan of the apes" were made in Shenzhen, but the value was small because of lack of originality. Having investigation and analysis, we find that although the creative industries in China have a considerable scale in quantity, the industries with more higher originality and innovation, such as film and television, culture, art, entertainment, etc, the performance in the industry is not outstanding[6]. It shows that "originality" as an original motive force is not enough in the development of industry. At the same time, the industry has also concentrated a large number of highly educated and high-tech titles of talents, belonging to knowledge intensive industries[7]. Thus, education and training institutions will become the cradle of creative talents. Also, the creative industries in Suzhou has a large distance, and the transformation and upgrading of creative industries is imminent.

The planning and development of creative industries in Suzhou determines the demand for art and design talents. Creative industry is a kind of endogenous growth model that is strongly depend on human creativity, and creative talents is an important backbone to ensure the smooth development of creative industries. Among the related industries involved in the creative industries, art design is an important field[8]. In Britain, the first development of the creative industry, architectural design, fashion design, advertising design, animation design, software design, visual arts, photography art, performing arts, music, publishing, broadcasting and other 13 arts and cultural industry were identified as the creative industry[9]. We can see that a number of industrial projects and art design have a direct relationship. Ceng Hui, the design of the Arts Council Secretary General in Chinese Artists Association, said in the art design education issues, "the design, education and design industry itself is an important part of the cultural and creative industries. We encourage independent innovation, that is, emphasis on design Innovation, China has become a very important supporter in the changing process from the manufacturing center to the creative center, in which design education provides a powerful driving force for the development of design industry of China". At present, creative talents have a large gap in quantity and quality, which is not compatible with the flourishing and development of creative industry. The proportion of employed employees in creative industries is only 1/1000, which is far lower than that that of Europe and America[10]. It is not only shortage of quantity, but also the imbalance of the structure. Some experts predict that the creative industry will continue to grow at a rate of $15 \%$ in China in the future. To maintain this pace, the training of creative talents is a priority. Creative talents, in the true sense, are the high-level talents who is independent intellectual property rights as the core, characterized by brain service, and using professional or special skills as a means. They have a deep understanding of the industry and innovation combining with practical [11]. However, the comprehensive talents of high-end who not only understand of the the creative design, but also can commercial operation are very lacking in the creative talents team. Especially the cultivation of innovative talents are our new task in training strategy. Among them, the cultivation of art and design talents is an important aspect that can not be ignored.

We mainly study the problem of how to reconcile the contradictions of the existing education system and creative industries of art and design majors in Suzhou. we found that art design specialties occupies a large proportion in the development fields, and the shortage of talents is the main reasons of hindering the development of the industry based on the investigation of the development of creative industries in Shanghai, Beijing and other places. Cultural innovation is the core issue of the Innovation and development of creative industries. The education and training of a large number of creative talents are a prerequisite for the great development of our creative industries because creativity comes from people [12]. Therefore, training first-rate creative talents, strengthening creative industries, and focusing high-end talents team are the key to training creative industries, in which talents are the soul of creative industries. In the well developed creative industries countries, such as United States, Japan and other places, they have addressed great importance to education, actively improved the creativity of the people, paid attention to the training and excavation of qualified personnel, and laied stress on the solid foundation of accumulation. The design courses in most schools in Suzhou only focus on the design of a single course but ignore the training of comprehensive knowledge. 


\section{Key Points and Difficulties}

Renew the Educational Idea, Establish the Market Consciousness and Set up the Value Idea. Art and design education trains highly qualified applied technical talents, and the students must have the corresponding knowledge and creative ability. Schools should establish a platform for self-study of courses to meet the needs of students in art and design majors in a maximum extent. Students can choose different courses according to their own preferences, so as to consolidate and expand their professional knowledge. For example, broaden the students' minor courses to enhance their employment opportunities; Integrate related disciplines by implementation of the credit system and breaking the pattern of discipline and specialization; Strengthen the dissemination and teaching of traditional culture, improve the cultural heritage of students; Learn new theories and techniques to make up for deficiencies in required courses. In addition, in the teaching, teachers should strive to pass through the knowledge of various disciplines in the entire process of art design education. Teachers can separate the projects and research into a number of topics according to the teaching objectives and requirements. With the development of the times and the progress of science, higher demands have been put forward to art and design Education. The cultivation of innovative ability has become the core of quality education in Colleges and Universities. At present, it is a common problem in art and design education that the curriculum content of art and design discipline is obsolete and cannot keep up with the development of discipline. Many schools have various disadvantages. Most colleges and universities have their own courses that are lack the scientific and integrity of the teaching system. It will seriously affect the quality of teaching and the realization of educational goals If is not adjusted in time.

Integrate Relevant Subjects and Blur the Boundaries of Specialty. Art design is a comprehensive subject with rich connotation. It is developed and evolved from the basis of traditional arts and crafts design. The knowledge involved in the traditional art design is not broad enough, and the degree is not deep enough. The exploration and research to the related subjects has not reached the depth of art and design education, which fully showing that art and design of China is still in a relatively low stage of development. Although the art and design education in China has also noticed the development of the related disciplines, and made corresponding adjustments and reforms. However, the overall impact on art and design education, as well as the art design of the relevant subject knowledge of more scientific are not enough. It presents in many aspects: art and design education to the knowledge of relevant disciplines is not enough; too special and the scope of education not wide enough, and the education methods relatively simple and so on. These also make our students are lack of broad vision and innovative thinking, with some conservative and rigid in their thinking. What society needs are comprehensive talents, who has the best interpretation of the interaction and infiltration of professional skills and comprehensive quality. It is known that the cultivate compound talents are from the compound education. The creative talents trained in art design education can not only have good performance in the specialized field, but also should have high comprehensive quality, including psychological quality, cultural quality and ideological quality. The compound education talents should have the following characteristic in the knowledge, the ability, and the quality aspect.

The multiple design teaching mode is effect way to cultivate design talents who have multiple creativity, establishes above the multi-disciplinary systematic knowledge foundation. First of all, it should also have the knowledge of the adjacent specialties based on the the basic knowledge of the major. Secondly, creative ability is the ability that the art design profession must have. Design comes from originality, the process of design is a creative work of the project. Finally, the comprehensive talents should received the compound education in ideological and moral, cultural, physical and mental qualities, etc. In the new era of creative industries, the complex talents can adapt and promote the development of society, and make greater contributions to the society. The progress of mankind has brought about the progress of society, and the progress of society has promoted the progress of mankind. Today, the compound talents palys the principal role as the technology and wisdom for the benefit of mankind in the world without them, scientific and technology will lost the its active position and meaning of existence, there is no social production 
and development. Therefore, the transformation from special education to compound education is an urgent and arduous task. It needs the positive promotion of educational management departments and tries hard to develop teaching ways.

Training the Creative Talents and Adapt to the Development of Industry. Today's society are characteristics of global, dynamic and digital. Art and design education are also facing the global competition. More and more educational resources are shared in the world, and single and conservative educational models must introduce dynamic mechanism and take the international route. The education should have new school running consciousness, teaching mode and teaching system to deal with this educational situation. In this paper, we preliminarily analyzed the art design education, creative ability, personnel training model and teaching system. The art design education should adapt to the need of social and economic development, the concept of art design education suit the market demand of the talent cultivation, and to explore the characteristic of art design education in practice. It is necessary to change the concept of education, to take effective measures and explore actively, and to create favorable conditions for the teaching and research of art and design discipline. At present, there are many problems in the internal system of art and design education in China, which needs further reform, improvement and improvement.

Avoid the vulgarization tendency in cultural popularity in the process of training entrepreneurial talents.

The art and design in China tends to more diversified and openning. It developes on the basis of "bringing", and has certain achievements and characteristics after decades of development. However, it faces the modern global design situation due to the limitations of its use. We should pay attention to the importance of "inheritance". The art and design of China should bear the characteristics of Chinese own culture. In the education, we should recreate on the basis of traditional, nationality and locality, achieve innovative results and contribute to the revitalization of the traditional culture. The splendid traditional culture of ancient China is the cradle of our modern art and design. Without it, our design will be lost in depth and breadth. Cultural and artistic heritage, creative ability and national personality play an important role in the tducation because of the disadvantages of the present art and design education. In the course of modern art and design education, we should firstly resume the folk art inspection course, especially regional, thus students can comprehended or understand the connotation of Chinese traditional culture. We should also know the characteristics of the land where I was born and raised, then to make the art design more effective in local features. Secondly, some additional courses should be added to cultivate the aesthetic feeling of students'. Chinese traditional art is not only in the form, but also in the connotation of a perceptual grasp. By cultivating aesthetic psychology and intuition of beauty of students, they can improve their artistic accomplishment and artistic evaluation ability. Thus, the design will not lack art and cultural connotations. We should promote artistic investigation, many of the outstanding traditional art elements in China are hidden in the folk, need the designers to find and comprehend. "Folk songs collection ", that is to collect Chinese the natural things, then choice, refining and processing with vision and artistic. This is the improvement of one's own traditional artistic accomplishments, as well as a heritage of traditional culture. From this point, our present art and design education should introduce western modern design theory and draw lessons from western excellent design, but also inherit and carry forward Chinese traditional art. The design of the course should adopt the combination of Chinese and western and mainly based on Chinese art. we must not only emphasized the education of Chinese traditional art, but also pay attention to the combination of Chinese excellent art and western art, and highlights the localization, nationalization and uniqueness of China. Art and design education under the background of the creative industry puts the national characteristics and local features into In the modern design. We still need to think how to further exploration the reform and innovate the traditional art design education. We have to strengthen the quality education of the art and design professional in Universities, outstand national and regional characteristics of Chinese art design education, then we will show a new attitude and a new era style in the international art design education stage. The development trend of contemporary art design must be based on the local culture and the ideological essence, which will 
integrate in the modern art design trends. The spread of national culture and national spirit has become one of the important responsibilities of every designer. This requires A guidance of art design education on the basis of the education. it is imperative that integrate humanistic education into Chinese art and design education under the background of creative industries. the Humanistic spirit can not be lost when the market economy tide is mixed with some quick success and instant gains, as well as some unhealthy social trends sweeping. As a university, especially art and design, we should not only shoulder the responsibility of protecting the tradition and arousing the national spirit and ideal, but also integrating the humanistic spirit and the emotional emotion into the design. "people-oriented" is the ultimate goal of design, at the same time art, design, education and practice should be promoted. The art and design attach importance to characteristic development, also should pay attention to training the comprehensive ability of talents and cultivate the humanistic emotion of talents. This is the trend of international education. In domestic, the most important task of each school is to find its own features, identify of the own position, find the right path and the proper way. Only in this way the art and design education in our country is able to train all kinds of excellent design talents.

Avoiding the Ecological Crisis Under the Creative Industry. The film "Wuji" was criticized because the local natural landscape of "Bi Hai Tianchi" shooting in Shangri-La of Yunnan province was caused considerable damage when the film's production. Although the film "Wuji" was motivated by the pursuit of special effects of the film, which led to the destruction of the natural ecology according to the final investigation of the relevant departments. It is no doubt that the local government wants to use the beauty of Shangri-La to earn economic benefits. It had caused serious damage to the environment, and the problem can not be ignored. A large area of Alpine azaleas was destroyed, garbage was everywhere, and the original ecological landscape wasdemaged and can not be restored so far by the barbaric production of the crew who borrowed the creative industries as the sweet excuse. Therefore, it has become the throes of modern cultural heritage in grasp the essence of traditional culture and to continue the excellent humanistic spirit of the nation.

Avoiding the Lack of Self in the Context of Industrialization. The Dragon Boat Festival on May $5^{\text {th }}$ in Chinese lunar calendar has been an ancient festival of China for thousands of years. But someday when a news suddenly pops out that the Dragon Boat Festival suddenly turns into "Jiangling Dragon Boat Festival" in South korea", and became Korea's "World Intangible Cultural Heritage". the news has largelyy stimulated the nerves of Chinese people. Although the Dragon Boat Festival in Jiangling is not the same as the Dragon Boat Festival handed down by the ancestors of China, the positive and effective behavior of the protecting on the national cultural heritage of the neighboring countries let us reflect on it. Such examples are too numerous to mention.

Breakthrough. First, we should encourage students to innovative, and affirm their creativity and exploration. Set up the view of learning and education with the pride of "creative and creative, taking plagiarism as shame". Second, teachers should explore the methods and measures of research efforts to guide the development of students' imagination, such as to provide a good learning platform for diversity and environment, let the students observe, practice, absorb the art and knowledge of related disciplines, get inspiration from. Third, we should strengthen the inheritance and innovation of local culture and national characteristics. Artistic features and uniqueness are the vitality of the work, so as to avoid imitating and copying western design styles blindly.

\section{Conclusion}

The development of creative industries can not only provide us more spiritual products, create a better cultural atmosphere, but also provide an unlimited opportunity for the innovation of traditional culture. At the same time, we should also realize that when the fragile cultural ecology faces huge economic interests, it needs the "cultural guards" to give an active guidance and protection. The creative industries will provide more long-term spiritual wealth, people's lives will be more "humane" charm under a good deal relationship between economic benefits and social 
benefits. The "culture" of human beings can permanently maintain in a unique sense and value of the times.

\section{Reference}

[1] B. Jiang; Decorative [In Chinese], Vol. 9 (2007) No. 9, p. 400.

[2] H. P. Xiaotao: Creative China and Cultural Industry (Jinan University press, China, 2007), p. 105.

[3] S. Z. Wang: History of World Graphic Design, (China Youth Press, China, 2002) , p. 9.

[4] Xitang Yuan: A study on the Ddevelopment of Chinese art and Design Education (Beijing Institute of Technology press, 2003), p.7.

[5] Q. M Zhao: Formation and training of innovative ability (Huazhong University of Science and Technology press, 2002), p. 50.

[6] X. Z. Tao: Cultivation of creative ability (Beijing ocean tide press, 2002), p.25.

[7] W. H. Chen: Aesthetics of Art and Design (Wuhan University press, 2000), p.56.

[8] Y. Z. Li: Introduction to art and design (Hubei Fine Arts Publishing House, 2002), p.45.

[9] H. P. Zhu: World History of Modern Design (HeFei University of Technology press, 2004), p. 8.

[10] M. Chen: Introduction to world art creative thinking (Anhui University press, 2006), P. 6.

[11] X. Liu: Some thoughts on the reform of Chinese art and Design Education. Teaching Forum [In Chinese], Vol. 12 (2007), No.3, p 35.

[12] Z. Y Yao: Journal of Jinling Institute of Technology $\quad$ [In Chinese], Vol. 12 (2007), p.78. 